Archives

$35 \mid 2005$

Indexer les exempla médiévaux

\title{
Présentation
}

\section{Bernard Vincent}

\section{(2) OpenEdition \\ Journals}

\section{Édition électronique}

URL : http://journals.openedition.org/ccrh/3007

DOI : $10.4000 /$ ccrh.3007

ISSN : 1760-7906

\section{Éditeur}

Centre de recherches historiques - EHESS

\section{Édition imprimée}

Date de publication : 10 janvier 2005

ISSN : 0990-9141

\section{Référence électronique}

Bernard Vincent, «Présentation », Les Cahiers du Centre de Recherches Historiques [En ligne], 35 | 2005, mis en ligne le 24 mai 2011, consulté le 20 avril 2019. URL : http://journals.openedition.org/ccrh/3007 ; DOI : 10.4000/ccrh.3007

Ce document a été généré automatiquement le 20 avril 2019

Article L.111-1 du Code de la propriété intellectuelle. 


\section{Présentation}

\section{Bernard Vincent}

Dans le premier numéro des Cahiers du Centre de recherches historiques, il était dit que les Cahiers atteindraient l'objectif assigné «s'ils transmettent rapidement une image fidèle des activités scientifiques du Centre, en particulier de ses nouvelles orientations, qu'il s'agisse des thèmes étudiés ou des collaborations avec les universités françaises ou étrangères ». Depuis 1988, le contenu des livraisons successives ne s'est pas écarté de ce projet et le numéro présent pas davantage que ses prédécesseurs. Le dossier ici présenté est un reflet d'une journée d'étude qu'a consacrée le GAHOM (Groupe d'Anthropologie historique de l'Occident médiéval), au Thesaurus exemplorum Medii Aevi (ThEMA), base de données qui, désormais, met à la disposition de la communauté scientifique une recherche collective conduite depuis déjà trente ans. Les Varia comprennent trois études, deux émanant de chercheurs espagnols ayant bénéficié de bourses post-doctorales auprès de notre laboratoire et travaillant dans une perspective comparatiste. Enfin, un membre de notre formation livre les résultats d'une enquête sur l'infanticide qui renoue avec des travaux effectués naguère par d'autres chercheurs. De ce fait l'histoire médiévale, histoire moderne et contemporaine trouvent toute leur place dans ce Cahier, ce qui est à l'image d'un Centre qui abolit volontiers les cloisonnements chronologiques.

\section{AUTEUR}

BERNARD VINCENT

EHESS/CRH 